\title{
Slipped Capital Femoral Epiphysis
}

\author{
Wiliam J. Schnute, MD, CORR 1958;11:63-80
}

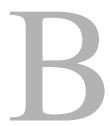

efore the turn of the $20^{\text {th }}$ century, the diagnosis of slipped capital femoral epiphysis (SCFE), as the condition now is understood, was not known. Traumatic separation of the epiphyses, however, was recognized much earlier, and according to Poland [13], perhaps the first recognition of epiphyseal separation was by Realdus Columbus in 1559. Earlier descriptions, he thought, were sufficiently imprecise to know whether the authors (and in particular, Hippocrates) were referring to the same entity. Poland's exhaustive work (926 pages, 337 illustrations and "skiagrams" or radiographs) from 1898, well documents previous contributions, but suggests it was not until 1759 when M. Geo. Christian Reichel clearly distinguished traumatic separation of the proximal femoral epiphyses from other diseases and injuries. (Readers interested in this history will find the complete work of Poland available at http://books.google. com/books?hl=en\&lr=lang_enllang_frl lang_dellang_it\&id $=58 \mathrm{v} 7 \mathrm{umad} 4 \mathrm{~A} 8 \mathrm{C} \&$ oi $=$ fnd $\& p g=P R 7 \& d q=$ separation + poland \&ots=XhviB_NcUB\&sig=bUzA3roemu $\mathrm{AWcNcQorzcNB} 0 \mathrm{Cx} 60 \# \mathrm{v}=$ onepage \&q $=$ separation $\% 20$ poland $\& \mathrm{f}=$ false.) Poland noted a common problem with those wishing to trace the history of medical disorders: "Various names have been applied...to these injuries, such as disjunction, divulsion, epiphyseal detachment or separation, juxta-epiphysial fracture and separation, epiphyseal diastasis." In addition, the diagnosis in preradiographic times was frequently imprecise or uncertain.

The recognition of nontraumatic slipped epiphysis in the upper femur oddly seems of rather more recent origin, although certainly there were many cases that either were undiagnosed or misdiagnosed (in the $19^{\text {th }}$ century, the term "arthritis deformans" frequently was applied to any number of painful hip conditions in patients of all ages, although it gradually came to suggest what we now think as osteoarthrosis). Monks [11], in 1888, described a 16-year-old boy with what likely was bilateral chronic SCFE, but he diagnosed arthritis deformans, having ruled out traumatic afflictions, congenital dislocation, and "dry caries" (presumably syphilis). According to Key [7] (article republished as a Classic in this issue of CORR, DOI 10.1007/s11999013-2913-y), investigators of the late $19^{\text {th }}$ century described cases of what we would likely consider SCFE, although they used various terms including bending of the neck of the femur in adolescence
Fig. 11 Case 7. April 15, 1950.

Original roentgenograms showing slipped capital

femoral epiphysis, right hip. (Reprinted with permission and (C) Lippincott Williams \& Wilkins from Schnute WJ.

Slipped capital femoral epiphysis. Clin Orthop.

1958;11:63-80.).
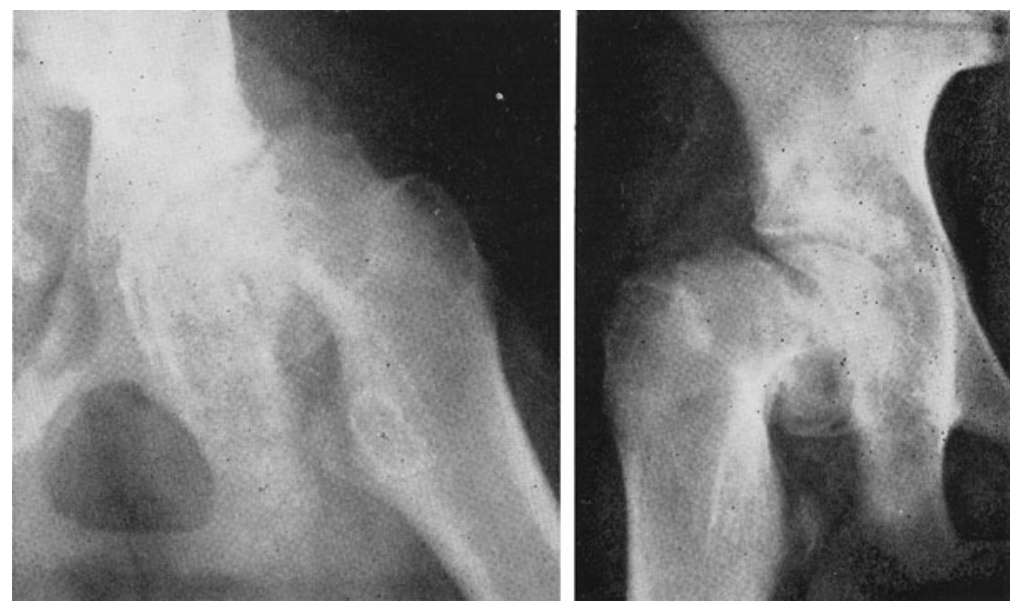


\section{Years Ago in CORR}

("Schenkelhalsverbiegungen im Jungesalter") [12] and coxa vara [4, 9]. Key properly noted, however, that coxa vara was merely descriptive and mentioned at least 12 conditions for which the anatomic term applied. Whitman [18], in 1902, described the case of a 16-yearold boy who most certainly had SCFE, and referred to the entity as "coxa vara of the epiphyseal type" in contrast to "coxa vara of the ordinary type." Key used the term, "epiphyseal coxa vara." He commented, "Epiphyseal coxa vara is not a common condition, yet it is probably the most frequent cause of disability in the hip, which begins in the adolescent period." However, he also used the term "slipped": "In closing the question of differential diagnosis, the most important point is that a traumatic or chronic hip beginning in adolescent life has about a fifty per cent chance of being a slipped epiphysis." Five years later, Hey-Groves [3] explicitly used the term, "slipped femoral epiphysis."

By the mid $20^{\text {th }}$ century, the term "slipped capital femoral epiphysis" had become the nearly universal English-language term for the condition. Schnute [14], in 1958, reviewed 16 patients with 21 hips having the disorder. He used either pinning-in-situ (four patients) or open reduction and pinning (12 patients) (Figs. 11-13) although he never clearly suggested the indications for choosing one over the other. In his small series, there were 10 boys and six girls, and he neither observed nor commented on the predominance in boys typically reported by more recent investigators $[2,6,16]$. He mentioned the body habitus in only two of the 16 patients, although obesity is a known risk factor today [16]. He advised against preoperative traction in patients with chronic slips: "...it seems inconceivable that traction or any manipulation could
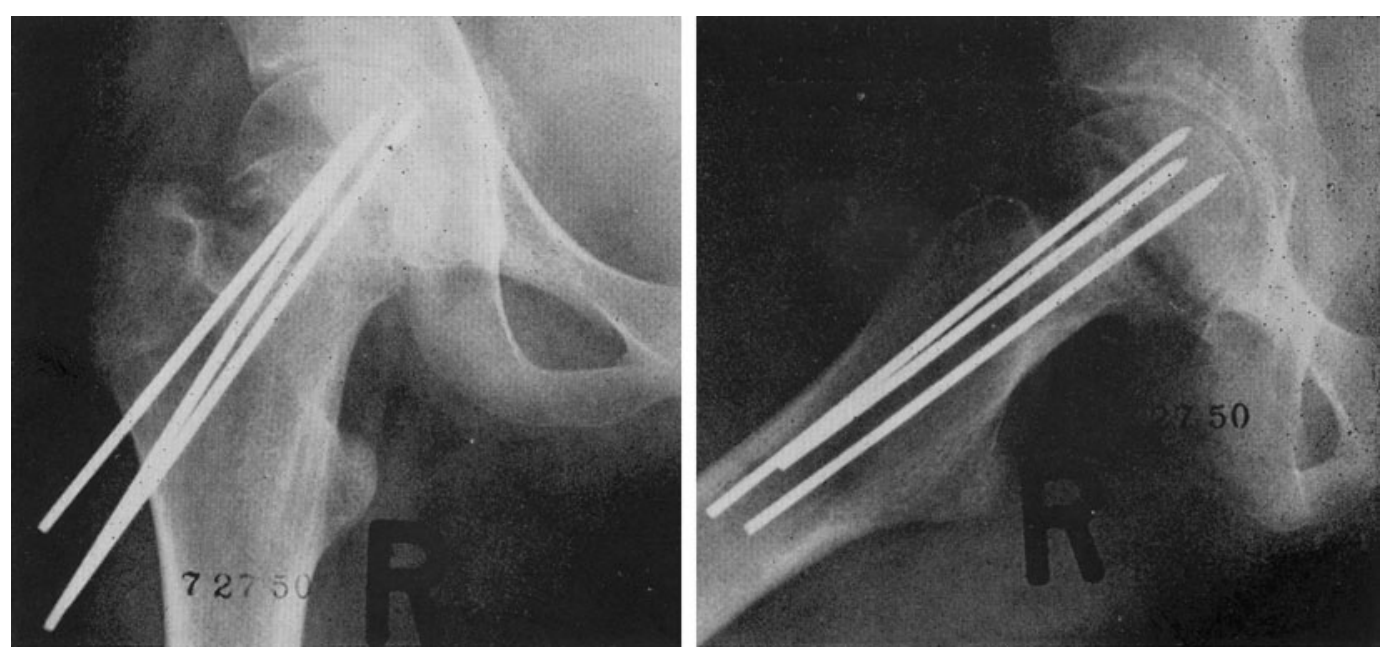

Fig. 12 Case 7. July 27, 1950. Three months after open reduction and threaded wire fixation. (Reprinted with permission and (C) Lippincott Williams \& Wilkins from Schnute WJ. Slipped capital femoral epiphysis. Clin Orthop. 1958;11:63-80.). 


\section{5 (reats Ago in CORR}
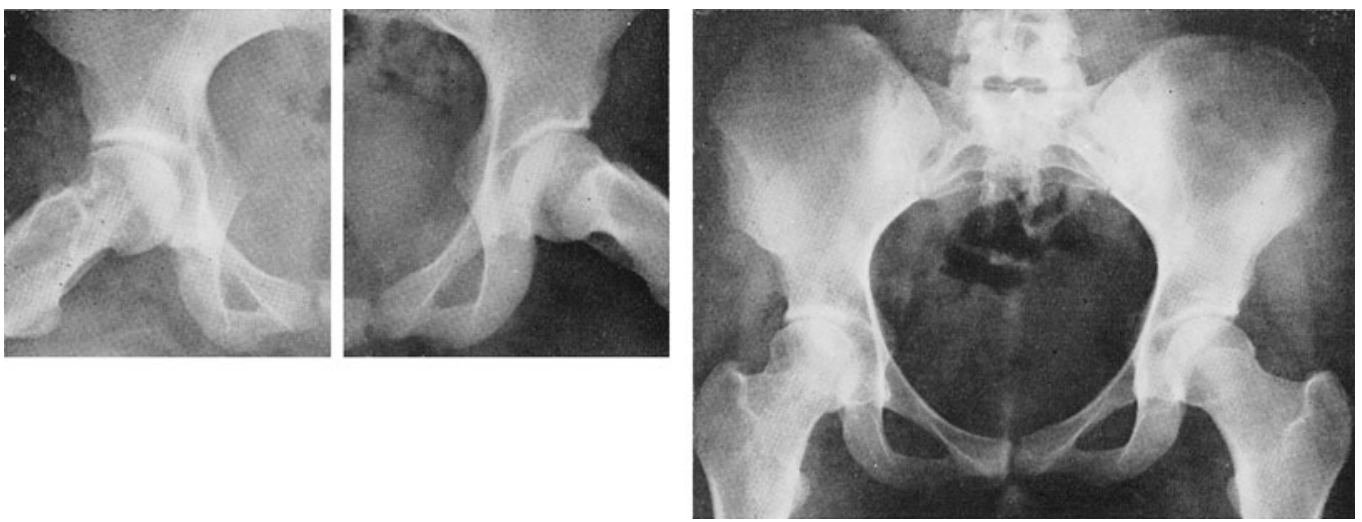

Fig. 13 Case 7. July 15, 1957. Seven years and 3 months after operation. Right hip entirely asymptomatic. (Reprinted with permission and (C) Lippincott Williams \& Wilkins from Schnute WJ. Slipped capital femoral epiphysis. Clin Orthop. 1958;11:63-80.).

possibly alter the position of the head of the femur, unless the slip has been acute within a period of 3 or 4 weeks prior to treatment." In some patients he used a wedge osteotomy of the femoral neck to correct more severe deformity. However, Schnute emphasized open surgery was as "technically difficult as, or more difficult than, any other single orthopaedic surgical procedure" and well recognized the need to be gentle and avoid injury to the vasculature to avoid necrosis. He further suggested prophylactic pinning of the unaffected hip.

Most surgeons now agree mild slips can be treated with in situ pinning, and without the open approach used by Schnute. His recommendation to prophylactically pin the unaffected hip (and if so in which patients) remains controversial today $[1,8,15]$, and while authors advocating osteotomy of the femoral neck [10], proximal femur [5], or subtrochanteric region [17] for more severe slips describe few complications and reasonable function, the severity of slips for which these approaches should be used also remains controversial.

Richard A. Brand MD Editor-in-Chief Emeritus Clinical Orthopaedics and Related Research

\section{References}

1. Baghdadi YM, Larson AN, Sierra RJ, Peterson HA, Stans AA. The fate of hips that are not prophylactically pinned after unilateral slipped capital femoral epiphysis. Clin Orthop Relat Res. 2013 Jan 3. [Epub ahead of print].

2. Hagglund G, Hansson LI, Ordeberg G. Epidemiology of slipped capital femoral epiphysis in southern Sweden. Clin Orthop Relat Res. 1984; 191:82-94.

3. Hey-Groves EW. An address on stature and pose: the problem of unequal legs. Br Med J. 1931;2:1-5.

4. Hofmeister F. Coxa vara. Eine typische Form der Schenkelhalsverbiegung. Beitr klin Chir. 1894;12:245-318. 
5. Imhauser G. [Late results of Imhauser's osteotomy for slipped capital femoral epiphysis (author's transl)][in German]. Z Orthop Ihre Grenzgeb. 1977;115:716-725.

6. Kelsey JL, Keggi KJ, Southwick WO. The incidence and distribution of slipped capital femoral epiphysis in Connecticut and Southwestern United States. J Bone Joint Surg Am. 1970;52:1203-1216.

7. Key JA. Epiphyseal coxa vara or displacement of the capital epiphysis of the femur in adolescence. $J$ Bone Joint Surg Am. 1926;8:53-117.

8. Kocher MS, Bishop JA, Hresko MT, Millis MB, Kim YJ, Kasser JR. Prophylactic pinning of the contralateral hip after unilateral slipped capital femoral epiphysis. $J$ Bone Joint Surg Am. 2004;86:2658-2665.

9. Kocher T. Ueber coxa vara. Eine Berufskrankheit der Wachstumsalter [On coxa vara. An occupational disease of growing children][in German] Deutsch Zeitschr Chir. 1894;38: 521-549.
10. Leunig M, Slongo T, Kleinschmidt M, Ganz R. Subcapital correction osteotomy in slipped capital femoral epiphysis by means of surgical hip dislocation. Oper Orthop Traumatol. 2007;19:389-410.

11. Monks GH. A case of unusual deformity of both hip joints. Boston Med Surg J. 1886;115:468-470.

12. Muller E. Ueber die Verbiegung des Schenkelhalses im Wachstumsalter: ein neues Krankheitbild [On the bending of the femoral neck during growth][in German]. Beitr klin Chir. 1888;4:173.

13. Poland J. Traumatic Separation of the Epiphyses. London, UK: Smith Elder \& Company; 1898.

14. Schnute WJ. Slipped capital femoral epiphysis. Clin Orthop. 1958;11: 63-80.

15. Schultz WR, Weinstein JN, Weinstein SL, Smith BG. Prophylactic pinning of the contralateral hip in slipped capital femoral epiphysis: evaluation of long-term outcome for the contralateral hip with use of decision analysis. J Bone Joint Surg Am. 2002;84:1305-1314.

16. Song KS, Oh CW, Lee HJ, Kim SD; Multicenter Study Committee of the Korean Pediatric Orthopedic Society. Epidemiology and demographics of slipped capital femoral epiphysis in Korea: a multicenter study by the Korean Pediatric Orthopedic Society. J Pediatr Orthop. 2009;29:683-686.

17. Tjoumakaris FP, Wallach DM, Davidson RS. Subtrochanteric osteotomy effectively treats femoroacetabular impingement after slipped capital femoral epiphysis. Clin Orthop Relat Res. 2007;464:230-237.

18. Whitman R. VII: A new method of treatment for fracture of the neck of the femur, together with remarks on coxa vara. Ann Surg. 1902;36:746-761.

50 Years Ago in CORR:

Slipped Capital Femoral Epiphysis Wiliam J. Schnute, MD

Richard A. Brand MD 